\title{
Mucocele frontal lateral, tratamiento combinado endoscópico y externo. Caso clínico
}

\section{Frontal lateral Mucocele, combined endoscopic and external treatment. Clinical case}

\author{
Emilio Godoy $\mathrm{R}^{1}$, Fernando Godoy $\mathrm{S}^{2}$.
}

\begin{abstract}
RESUMEN
日 mucocele frontal es la ubicación más frecuente de los mucoceles de senos paranasales, sin embargo aún no hay consenso respecto a la técnica quirúrgica adecuada para su tratamiento. 1 presente trabajo muestra un caso clínico de un mucocele frontal lateralizado, que desplaza el globo ocular y lóbulo cerebral frontal. Se muestra la técnica quirúrgica empleada (vía externa combinada con vía endoscópica). Se exponen las distintas técnicas de imagenología diagnóstica y técnicas computacionales que ayudan en el procedimiento quirúrgico.
\end{abstract}

Palabras clave: Mucocele Frontal, Técnica quirúrgica Mucocele Frontal.

\section{SUMMARY}

Frontal mucocele is the most frequent mucocele in paranasal cavities, however, there is still no consensus with respect to the adequate surgical technique for its treatment. The present paper shows a clinical case of lateralized frontal mucocele, that displaces the eye ball and frontal brain lobe. The surgical technique applied is shown (external path combined with endoscopic path). The different imagery techniques are shown as well as computerized techniques that help with the surgical procedure.

Key words: Frontal Mucocele, frontal mucocele surgical technique.

\section{INTRODUCCIÓN}

日 mucocele frontal constituye alrededor del $60 \%$ de las ubicaciones de los mucoceles de senos para nasales ${ }^{1}$. Se caracterizan por su lento crecimiento y el desplazamiento paulatino de las estructuras vecinas.
Aunque la cirugía endoscópica de nariz y senos paranasales ha revolucionado el tratamiento de las distintas patologías rinosinusales, aún no hay consenso en lo que se refiere al tratamiento de los mucoceles frontales ${ }^{2}$.

\footnotetext{
${ }^{1}$ Médico Unidad Otorrinolaringología, Cínica Alemana de Temuco.

${ }^{2}$ Alumno Medicina, Universidad de la Frontera, Temuco.
} 
Por una parte, la técnica tradicional enfatiza en el abordaje externo y la remoción total de la cápsula del mucocele. Los procesos obliterativos dificultan el control imagenológico postoperatorio. Por otro lado la técnica endoscópica tiene el riesgo de recidiva ${ }^{3,4}$.

日 presente trabajo muestra un caso de mucocele frontal lateral, cuyo tratamiento resultaba imposible por vía endoscópica exclusiva, de manera que se realizó un tratamiento quirúrgico combinado por vía externa y vía endoscópica.

Se muestra también el estudio imagenológico del mucocele con tomografía computarizada multicorte, reconstrucciones tridimensionales, uso

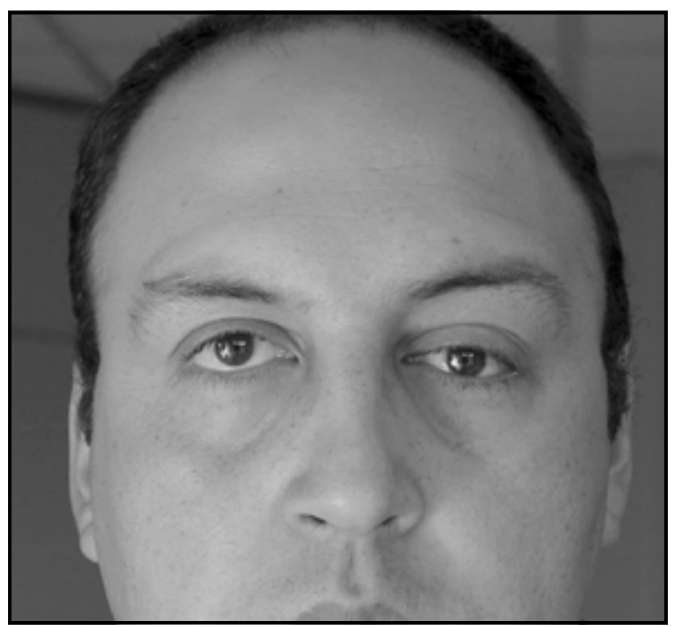

Figura 1. Cambio posición ocular ojo izquierdo.

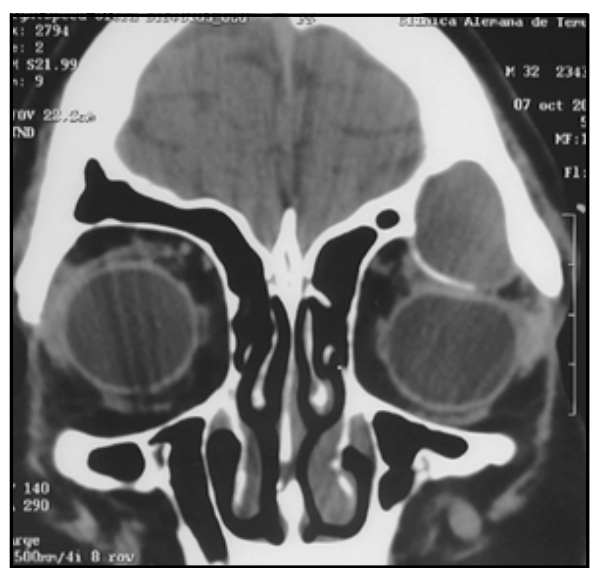

Figura 2. Corte coronal TC. de distintos colores para las distintas densidades de los tejidos. Resonancia nuclear magnética en T1 y T2. Se aplica un programa computacional de imágenes para lograr una exacta ubicación de la incisión cutánea respecto a la lesión.

Se muestra gráficamente el estado del paciente en el preoperatorio, la técnica quirúrgica y el postoperatorio luego de un año de la cirugía.

\section{CASO CLÍNICO}

Historia y estudio diagnóstico: Paciente masculino de 35 años sin antecedentes mórbidos de importancia, que relata desde hace 3 meses cambio de la posición de su ojo izquierdo hacia caudal y medial, diplopia en la mirada lateral, cefalea moderada y dolor ocular izquierdo (Figura 1).

La tomografía computarizada mostraba lesión homogénea en región lateral del seno frontal izquierdo, que desplaza el globo ocular hacia abajo y hacia medial (Figuras 2, 3, 4 y 5).

La reconstrucción tridimensional y con colores para las distintas densidades del tejido, ilustran de mejor manera la lesión y sus relaciones a las estructuras vecinas (Figuras 6 y 7 ).

También la resonancia nuclear magnética muestra las relaciones del mucocele y las estructuras vecinas. En T2 podemos inferir que su contenido es líquido (Figuras 8, 9).

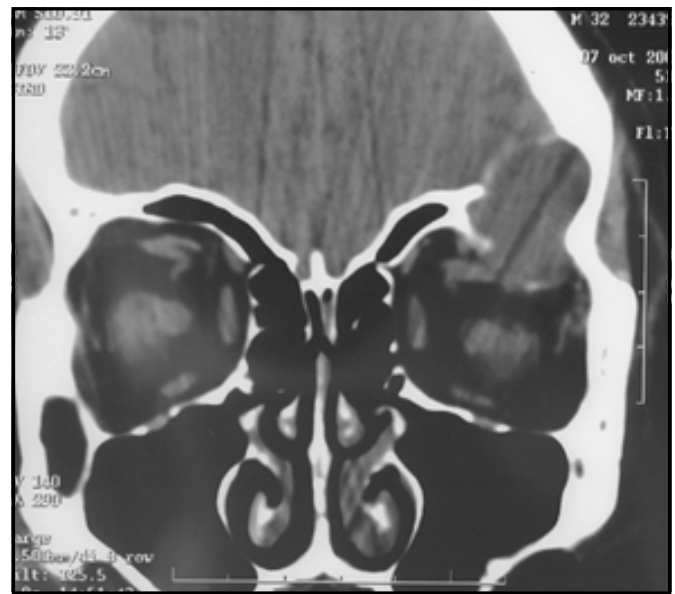

Figura 3. TC, corte coronal posterior. 


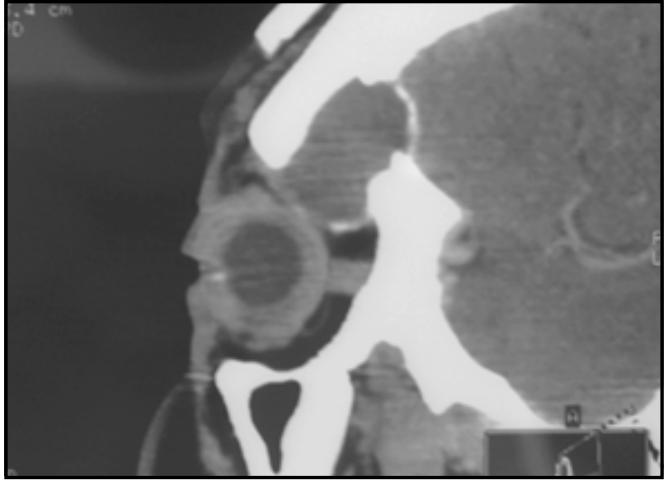

Figura 4. TC, corte sagital, muestra el desplazamiento ocular y polo del lóbulo frontal cerebral.

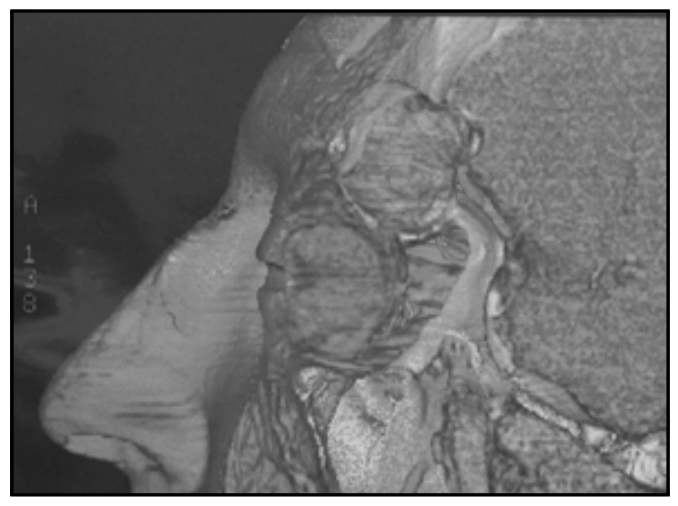

Figura 6. Mucocele en relación al globo ocular y cerebro.

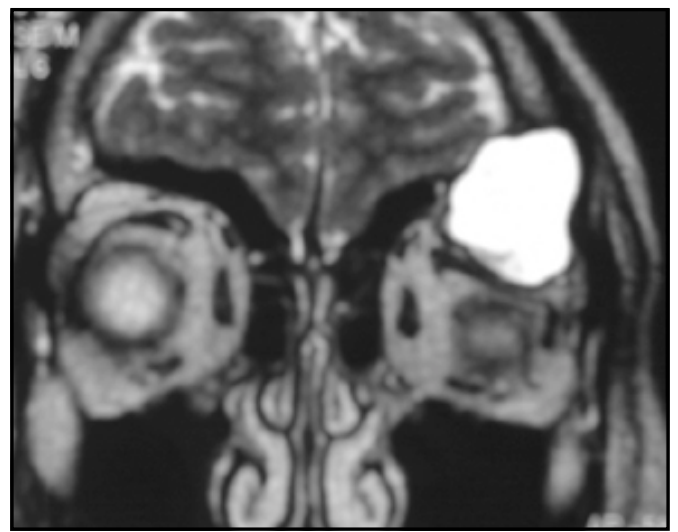

Figura 8. RNM, muestra contenido similar al LCR.

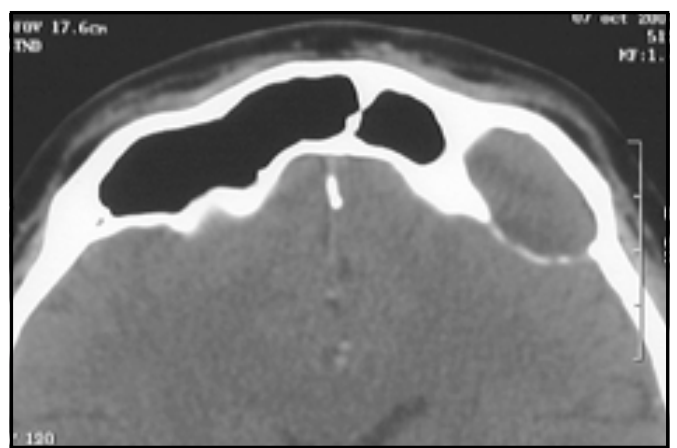

Figura 5. TC corte axial, que muestra además un tabique óseo entre el mucocele y el resto del seno hacia medial.

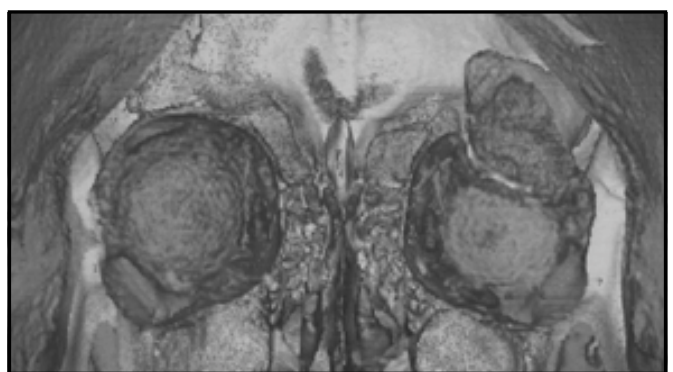

Figura 7. Reconstrucción coronal a nivel del mucocele y globo ocular.

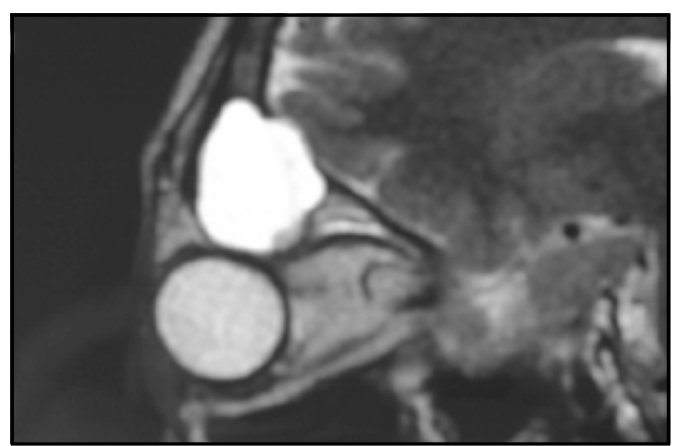

Figura 9. RNM, corte sagital. 
A realizar el abordaje externo resulta difícil una vez traspasados los planos superficiales el ubicarse con relación a la piel y la lesión propiamente tal. Para superar este problema se trabajó con la superposición de imágenes del TC y RNM con la cara del paciente, de manera que los puntos de referencia de la anatomía de superficie orientaran en relación a la lesión. Esto se logra con el programa Adobe Photoshop, manejo de capas, variando las opacidades de éstas (Figuras 10 y 11).

Técnica quirúrgica usada: Se contó con la asistencia como ayudante de un neurocirujano para la eventualidad de realizar un abordaje coronal, lo que afortunadamente no fue necesario. Se realizó un abordaje externo por los planos superficiales hasta el hueso frontal. Se taladra un orificio en la parte centro-

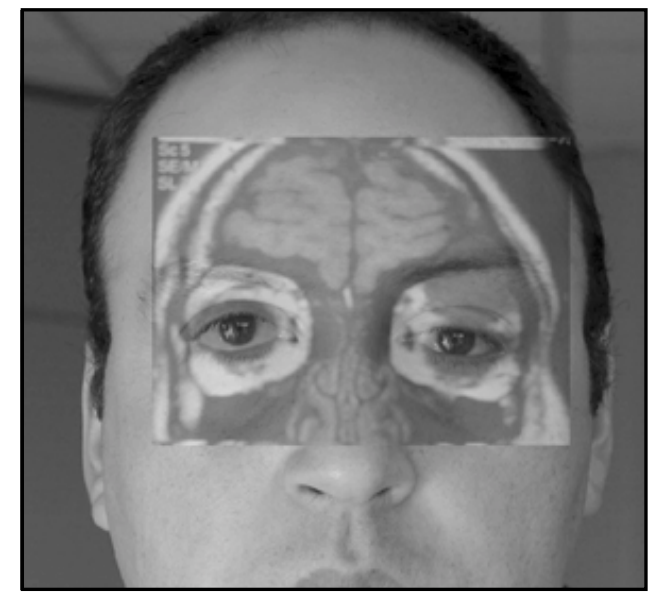

Figura 10. Superposición de RNM y rostro del paciente.

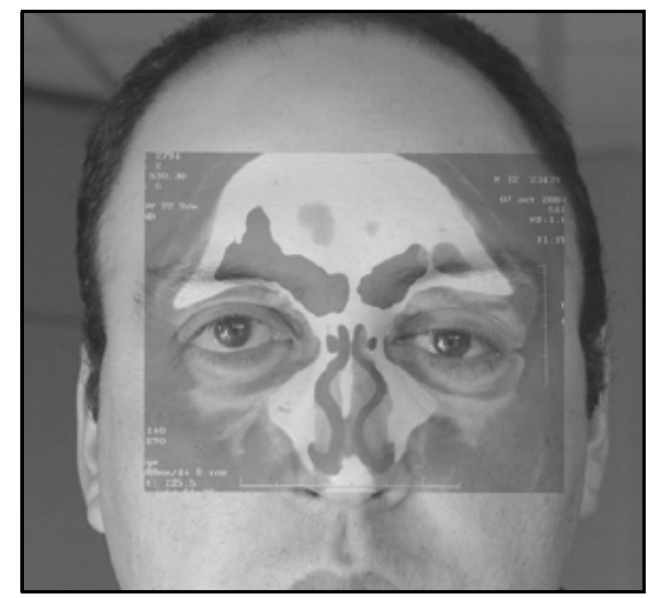

Figura 11. Superposición de TCy rostro del paciente. medial del seno, se explora con óptica de $45^{\circ}$, se procede a abrir una ventana ósea con sierra oscilante, con corte en bisel, sacando totalmente parte de la pared anterior del seno frontal, lográndose amplia exposición del mucocele (Figuras 12, 13 y 14).

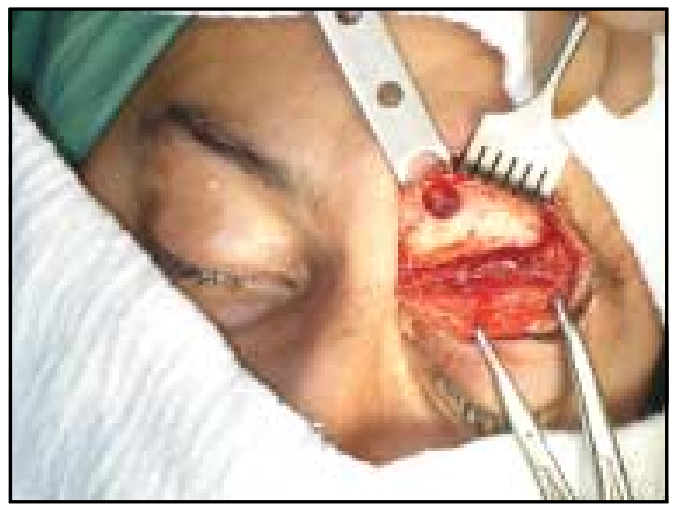

Figura 12. Perforación inicial del seno.

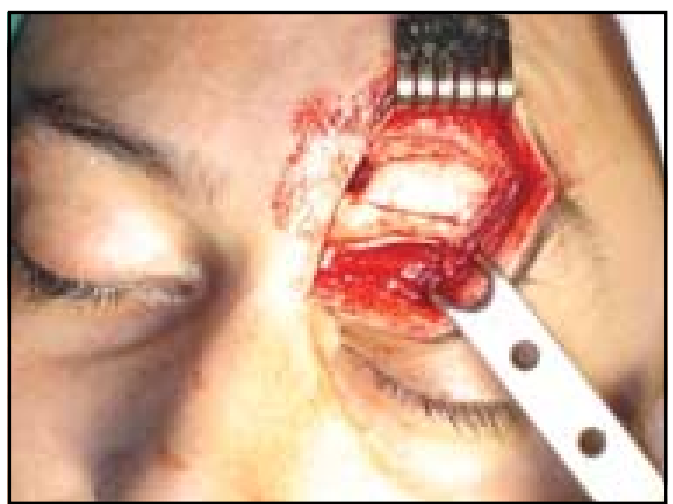

Figura 13. Muestra las líneas de corte sobre la pared anterior del seno.

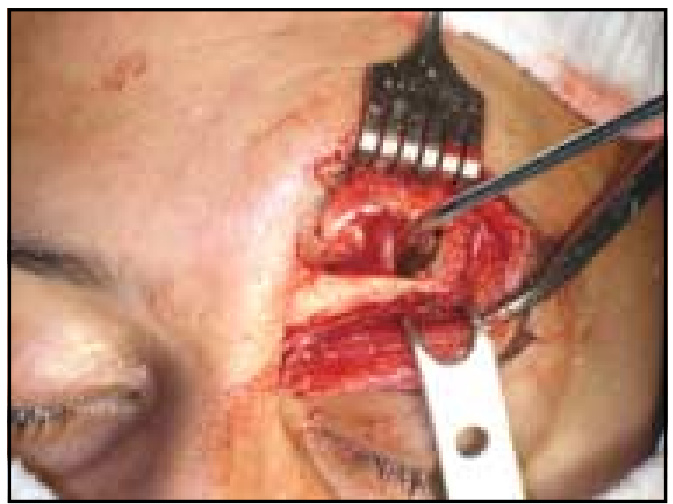

Figura 14. Muestra el seno, la cavidad del mucocele y el tabique óseo rebajado. 
日 corte en bisel en todas sus aristas, de manera que la tabla externa tuviera mayor superficie que la tabla interna, permitió posteriormente la recolocación de la tapa ósea de la pared anterior con su total coaptación (como un encaje), no siendo necesario el uso de placas u otro elemento de sujeción.

Luego de drenar el mucocele, se comprueba a través del latido pulsátil del cerebro y la órbita que no hay estructura ósea, de manera que sólo se extirpa la cápsula del mucocele que está en relación a la cavidad del seno, esto correspondía aproximadamente a $30 \%$ de la cápsula.

Mediante abordaje endoscópico se realiza: infundibulotomía, etmoidectomía anterior y media, lográndose una amplia visualización del trayecto nasofrontal, incluso visualizando el seno frontal desde la cavidad nasal con óptica de $45^{\circ}$.

Se procede a explorar el trayecto nasofrontal tanto por vía endoscópica como desde el mismo seno frontal. Se comprueba su permeabilidad y se deja un tubo en T de drenaje, el cual se retira a los 5 días.

Se reinstala la tapa ósea extraída de la pared del seno frontal.

Se sutura por planos la incisión. 日 paciente es dado de alta 2 días después en perfectas condiciones.

Se realizan controles clínicos, endoscópicos semanales, quincenales y mensuales hasta un año después. Se controla con nuevo TC de senos paranasales al año postoperatorio. Tanto clínica mente como en las imágenes del TC de control, se observa una desaparición de los síntomas y un lento reestablecimiento de la anatomía normal del paciente (Figuras 15, 16, 17, 18, 19, 20).

\section{DISCUSIÓN}

En la sintomatología de este caso de mucocele, así como otros que se presentan en el seno frontal, destaca la cefalea, dolor ocular, diplopia y cambios en la posición del ojo del lado afectado 5 .

日 estudio imagenológico con TC multicorte y reconstrucciones tridimensionales, además, con la posibilidad de asignar colores a las distintas densidades del tejido, dan una más clara ubicación anatómica de la lesión. Lavariedad de T2 de la RNM, nos indica que se trata de líquido similar al LCR.

En este caso dado que la cápsula del mucocele se hallaba en directo contacto con la meninge y los elementos de la órbita, se optó por no tocar la cápsula en estas zonas y se resecó lo más posible hacia la cavidad del seno frontal.

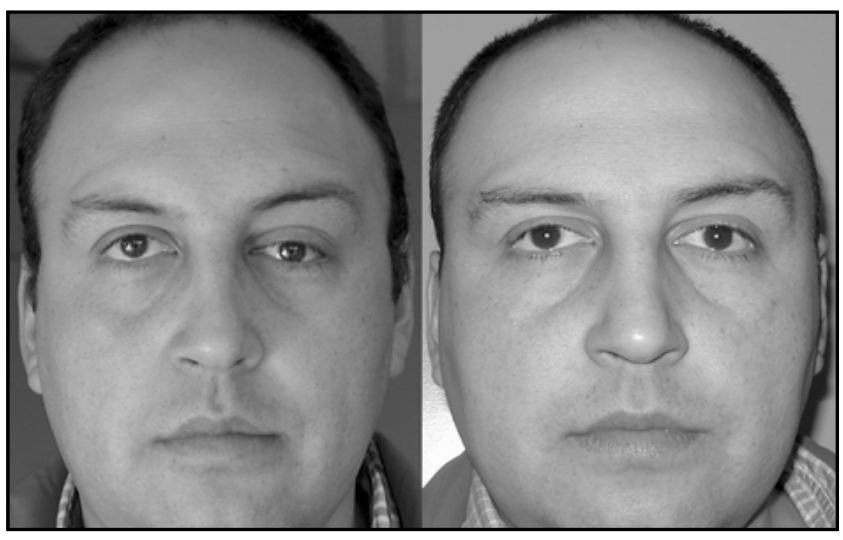

Figura 15. Preoperatorio y un año postoperatorio. 日 ojo izquierdo ha recuperado casi totalmente su posición y la cicatriz del abordaje es casi imperceptible.

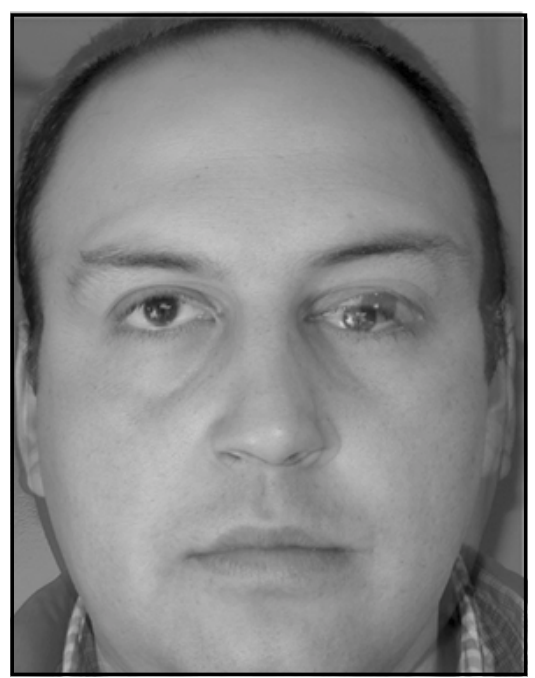

Figura 16. Superposición de imágenes pre y postoperatorias, se observa el desplazamiento del globo ocular. 


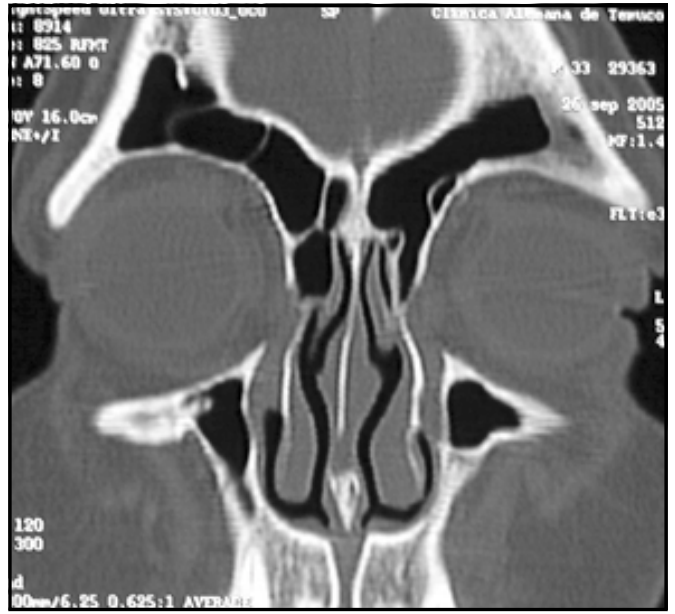

Figura 17. TC coronal 1 año postoperatorio.

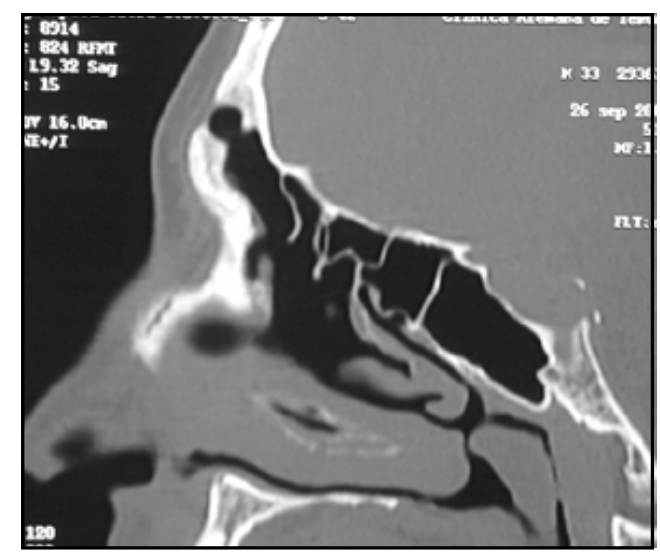

Figura 19. TC sagital 1 año postoperatorio. Nótese la perforación de exploración inicial y la comunicación del seno hacia fosa nasal.

La combinación de un abordaje externo con la vía endoscópica resulta del todo conveniente, para asegurarnos que no exista una posterior recidiva.

日 seguimiento del paciente, a la fecha más de año ha sido del todo satisfactorio.

La incorporación de técnicas de superposición de imágenes (capas) de la cara del paciente y del estudio imagenológico, con el programa Photoshop resultó de gran ayuda en la orientación una vez abiertos los planos superficiales.

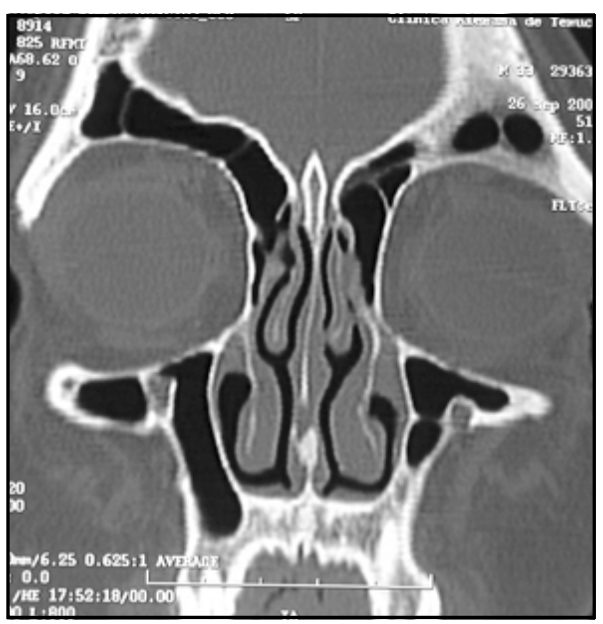

Figura 18. Corte coronal TC un año postoperatorio.

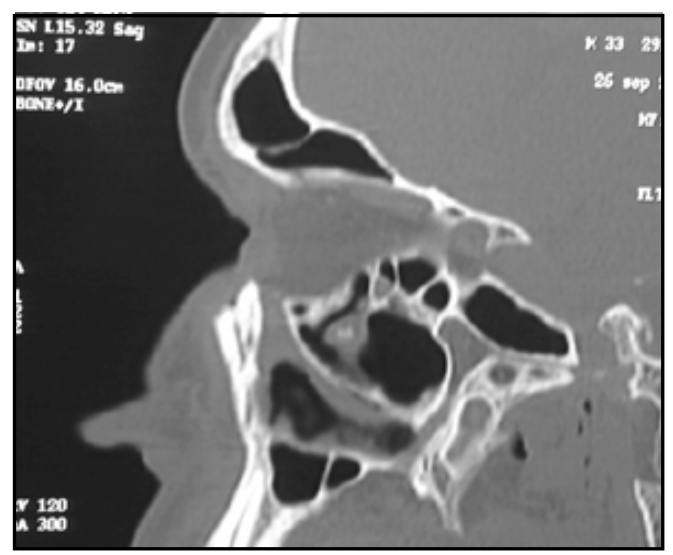

Figura 20. Corte sagital, se observa restablecimiento de la pared posterior del seno frontal.

Por ultimo, es la opinión de este autor que la remoción completa de la cápsula del mucocele no fue necesaria, al lograr marsupializar adecuadamente el mucocele al seno frontal y éste, a la vez, contar con un adecuado drenaje.

Por último la movilización total de un trozo de la pared anterior del seno frontal, mediante un corte en bisel en todas sus aristas, hace más fácil la reposición anatómica sin requerir placas u otro medio de sujeción. 


\section{BIBLIOGRAFÍA}

1. RODRíGUEZ, TORANZO, LOYOLA. Mucocele gigante del seno frontal (reporte de un caso clínico) Revista ADM VOL. LVIII., № 1 Enero-Febrero 2001; 58: 36-37.

2. KENNEDY DW, JOSEHSON JS, ZINRECH SJ ET AL. Endoscopy sinus surgery for mucotes: a viable alternative. Laryngoscope 1989; 118: 142-6.
3. HAR-EI G Trannasal endoscopic management of frontal mucoceles. Atolaryngol Cin North Am 2001; 34: 243-51.

4. KUHN FA, JAVER AR. Primary Endoscopic Management of frontal sinus. Otolaryngol Cin North Am 2001; 34: 59-75.

5. SANTOYA, VAREA, SANDOVAL. Mucocele intracraneal comunicación de un caso. Rev Méd Chile 2000; 128 (3): 319-22. 